\title{
Estresse em professores de educação infantil: um estudo bibliométrico
}

\author{
Luciana Amaral Garcia ${ }^{1}$ \\ Orcid: http://orcid.org/0000-0001-9095-7276 \\ Maély Ferreira Holanda Ramos ${ }^{2}$ \\ Orcid: http://orcid.org/0000-0001-6150-6345 \\ Jamille Gabriela Cunha da Silva ${ }^{3}$ \\ Orcid: https://orcid.org/0000-0002-8666-6043
}

\begin{abstract}
Resumo
Apesar dos significativos avanços em prol da qualidade no ensino da Educação Infantil, as condições de trabalho e saúde do docente estão sendo negligenciadas. O objetivo da pesquisa foi levantar dados a respeito da produção acadêmica sobre Estresse e Professores de Educação Infantil entre os anos de 2008 e 2018 . A pesquisa é bibliométrica e possui abordagem quantiqualitativa, utilizando da técnica de revisão da literatura e da análise de redes de coautoria e conexões entre termos-chave. Os resultados revelaram que há um grupo de pesquisadores que se relaciona e publica sobre a referida temática e estabelece tímidas relações com outros grupos de pesquisadores. A rede de palavras-chave aponta que o descritor "educação infantil" exerce e recebe influência de grupos de igual e diferentes áreas. Considera-se relevante que a temática tenha pesquisas mais aprofundadas, por meio de novas parcerias entre pesquisadores, e a expansão das conexões com outras áreas da ciência.
\end{abstract}

Palavras-chave: 1. Professores de Educação Infantil 2. Estresse 3. Revisão da Literatura 4. Estudo Bibliométrico

\begin{abstract}
Despite the significant advances in favor of quality in the stage of Early Childhood Education, the work conditions and health of the teacher are being neglected. The objective of the research was to collect data about academic production on Stress and Teachers of Early Childhood Education between the years 2008 and 2018. The research is bibliometric and has a quantitative and qualitative approach, using the technique of literature review and network analysis coauthorship and connections between key terms. The results revealed that there is a group of researchers who relate and publish on the referred topic and establish timid relationships with other groups of researchers. The keyword network points out that the descriptor "early childhood education" exercises and receives influence from groups of equal and different areas. It is considered relevant that the theme has more in-depth research, through new partnerships between researchers, and the expansion of connections with other areas of science.

Keywords: Kindergarten Teachers. Stress. Literature Review. Bibliometric Study.
\end{abstract}

\footnotetext{
${ }^{1}$ Mestrado em Educação, Programa de pós-graduação em Educação/Instituto de Ciências da Educação, Universidade Federal do Pará, e-mail: luje2504@gmail.com

${ }^{2}$ Pós-doutorado em Teoria e Pesquisa do Comportamento, Programa de pós-graduação em Educação/Instituto de Ciências da Educação, Universidade Federal do Pará, e-mail: maelyramos@hotmail.com

${ }^{3}$ Mestrado em Educação, Programa de pós-graduação em Educação/Instituto de Ciências da Educação, Universidade Federal do Pará, e-mail: jamillegabriela22@gmail.com
} 


\section{Introdução}

As recentes mudanças legislativas sobre o reconhecimento da Educação Infantil como “a primeira etapa da Educação Básica", segundo a LDBEN no 9394/1996, trouxeram melhorias na qualidade desse seguimento, como a oferta de vagas para as crianças e a preocupação com a formação pedagógica para o docente nesse nível de ensino (MARTINS et al., 2014). Porém, a formação dos professores de Educação Infantil ainda necessita ser repensada e desvinculada, quando necessário, do tradicionalismo do trabalho docente, buscando-se, assim, uma prática pedagógica sólida que compreenda o processo ensino-aprendizagem do nível (RODRIGUES; SAHEB, 2015).

Pesquisas discutem que, além de uma prática efetiva, por meio do desenvolvimento de jogos e brincadeiras, ferramentas indispensáveis na educação de crianças pequenas (LYNCH, 2015), a formação do profissional que atua na primeira infância deve levar em consideração peculiaridades de cada sujeito, como as dos que apresentam alguma deficiência (DE VITTA; DE VITTA; MONTEIRO, 2010), e a conscientização dos direitos e deveres cívicos da criança para com o meio e a sociedade em que vive (SILVA; CUNHA, 2016). Além dessas, a modernidade impulsiona para que se faça o uso de novas tecnologias, como as Tecnologias da Informação e Comunicação (TIC's), cobrando que os professores se atualizem para incorporar tais tecnologias em suas aulas, pois já foi comprovado que estas motivam alunos pré-escolares (KONKA; OZEL; ZELYURT, 2016).

São muitos os papéis atribuídos aos professores em geral, em especial aos professores da Educação Infantil. Para alguns autores, a atuação do profissional que lida com crianças de 0 a 5 anos vai além de educador formal, pois atua como mediador do processo (PEREIRA; MAIMONE; OLIVEIRA, 2012) e também observador e defensor contra a violência e a favor da integridade da criança (GARBRIN et al., 2010). No entanto, se o profissional não estiver consciente do processo ensino-aprendizagem, suas práticas acabam não surtindo o efeito positivo esperado, levando a fragmentação de sua identidade para si e perante a sociedade, pois não consegue estabelecer relação dos seus atos com os objetivos a serem atingidos com os alunos em sala de aula (JESUS et al., 2013), gerando frustração e sentimentos depreciativos.

A Educação Infantil possui caráter próprio, e por se tratar das primeiras interações da criança com o ambiente escolar, as habilidades sociais devem ser bem-sucedidas, valorizando integralmente a criança, e, portanto, o profissional que atende meninos e meninas dessa faixa etária necessita estar apto para lidar com diferentes demandas (MAIA; SOARES; VICTORIA, 2009). Segundo Martins et al. (2014), essas demandas são de natureza burocráticas, morais, pessoais, profissionais, técnicas etc. e, se forem somadas às condições de trabalho insuficientes e à baixa remuneração, acabarão gerando o mal-estar docente, pois as adversidades do meio podem ser maiores do que a capacidade de lidar do docente.

Apesar do acervo teórico e legal conquistado historicamente, ainda hoje se percebe um abismo muito grande entre o que vem sendo pesquisado, o que está proposto na legislação e as práticas cotidianas observadas nas instituições de atendimento à infância, principalmente a respeito das condições do trabalho do professor de Educação Infantil (MOREIRA; TOMAZZETTI, 2018).

Na pesquisa de Martins et al. (2014), foi discutido que as mídias e os políticos atribuem a culpa pelo fracasso escolar às professoras que atuam na primeira infância, sem considerar que essas possuem uma jornada de trabalho estressante e procuram medicamentos ou são afastadas por motivos de saúde para que consigam administrar as tensões, principalmente do trabalho. Novos estudos sobre o real trabalho dos professores de Educação Infantil devem ganhar mais visibilidade para que não sofram julgamentos e reducionismos equivocados.

Ainda são recentes as inserções de temas como resiliência, estresse, educação emocional nas escolas, e eles vêm ganhando importância, pois acreditava-se que temas com valores 
intelectuais seriam os mais necessários em tal ambiente. Isso se deve às reflexões sobre o processo de humanização da sociedade, para que se consiga compreender o papel da subjetividade e das emoções, e o quanto essas têm sido negligenciadas nos espaços laborais. Com tal importância que a temática tem assumido perante os trabalhos acadêmicos, há ainda pesquisas que endossam tal necessidade, pois alegam que a preocupação com a saúde mental do professor deve ser discutida nas formações permanentes de professores para que haja apoio e ajuda nas transformações importantes da vida e trabalho, e não deve ser reduzida à formação técnica do docente (RHODEN; RHODEN, 2014).

Estudos recentes mostram o quanto é relevante o estudo do estresse do professor, em especial das fases em que se encontram da implicação da síndrome em outros aspectos da vida do profissional. Levando-se em consideração o grupo estudado, há trabalhos que verificaram que a síndrome do estresse pode afetar os relacionamentos dos docentes, implicando na dificuldade de relacionamento entre colegas de trabalho no ambiente laboral (FERGUSON; MANG; FROST, 2017). Em outro estudo com outra amostra, o estresse não foi um fator de distanciamento entre o professor e outros sujeitos, pelo contrário, as relações sociais e apoio social foram percebidos como fatores satisfatórios no manejo da situação pelo professor (ROCHA et al.,2017).

Pesquisadores já haviam comprovado em suas investigações que nem todos os docentes em situação de estresse têm sua satisfação com o trabalho diminuída. O estudo de Skaalvik e Skaalvik (2015) procurou indicar as fontes percebidas de satisfação no trabalho e estresse de 34 professores noruegueses. Os entrevistados relataram que as fontes de seu estresse são a carga elevada de trabalho, a ausência de tempo para planejar e a adaptação das aulas para alunos com necessidades especiais. Apesar disso, responderam possuir elevada satisfação no trabalho, motivada pela certeza da escolha certa para a carreira, o trabalho significativo com crianças, a autonomia que a educação norueguesa proporciona para que ocorram suas aulas e o trabalho em equipe com a responsabilização do grupo de professores por alunos de determinado nível de ensino. Apesar de os entrevistados indicarem ter passado por, pelo menos, uma situação estressante, esses compreendem o seu trabalho como uma ação benéfica em prol dos alunos.

A solução para demandas elevadas de estresse seriam as estratégias de coping ou enfrentamento. Autores perceberam que os professores entrevistados em sua pesquisa, que possuíam elevados índices de estresse no trabalho, optavam por conversar com amigos, familiares e colegas professores visando o alívio da tensão. No entanto, alguns desses círculos eram os geradores do estresse, o que não surtiu bons efeitos nos entrevistados. Porém, os autores trazem tipos diferentes de apoio social que podem ser executados no ambiente social, como o uso de mídias sociais on-line para a discussão dos problemas de trabalho e saúde em grupos anônimos e até mesmo uma rede de apoio de gestores para com professores, servindo de base para situações que possam estressá-los, como no caso do comportamento de alunos (FERGUSON; MANG; FROST, 2017).

No entanto, Silva e Salles (2016) apresentam como resultado de suas pesquisas que é pequeno o número de pessoas que conhecem tratamentos alternativos para lidar com o estresse e outras síndromes, e menor ainda é o grupo de pessoas que se submetem a tais tratamentos. Fato que alerta para a falta de importância que algumas pessoas atribuem ao estresse (SILVA; SALLES, 2016). As estratégias de enfrentamento precisam ser difundidas para conhecimento de todos os profissionais, inclusive professores, pois como já mencionado, trata-se de uma atividade laboral que gera demasiados níveis de tensões nos educadores. Há estudos que indicam o uso de estratégias de coping, sendo as de controlo ou de confronto as promotoras do engajament deste profissional. Já as estratégias de escape ou evitamento, que são utilizadas pelos docentes, elevam os índices de Burnout (POCINHO; PERESTRELO, 2011).

A partir da bibliografia, é perceptível a existência de pesquisas abordando tanto temáticas sobre Estresse quanto Professores de Educação Infantil. Seria provável que as 
temáticas aproximem estudiosos que possuem características e motivações diferentes. Sendo assim, torna-se crescente também a possibilidade em analisar essas colaborações (MAIA; CAREGNATO, 2008).

Uma técnica que pode fazer as mencionadas e outras análises de correlações é a Análise de Redes Sociais (ARS). Em especial, se tratando de estudo de palavras-chave e de coautoria, utiliza-se uma vertente dessa técnica, a Análise de Redes Semânticas. Essa executa a representação de uma teia de conceitos e a definição de um conceito em particular. Trata-se de um caminho metodológico novo, que visa compreender características complexas de fenômenos com a construção e difusão de conhecimento (SANTOS JÚNIOR et al.,2015).

Segundo um estudo realizado por Marteleto (2010), que pontuou os caminhos teóricos e metodológicos sobre a Análise de Redes Sociais, além dos estudos que utilizaram a metodologia, no campo da informação e comunicação envolvendo a Análise de Redes, tais pesquisas assumem dois focos: 1) analisar as redes de pesquisadores e de colaboração na ciência, em sua maior parte empregando a análise de coautorias e 2) Analisar redes sociais de empresas e atores políticos, sociais e econômicos.

Portanto, torna-se importante levantar a produção acadêmica a respeito do Estresse e dos professores da Educação Infantil, pois, ao se conhecer as conexões entre as temáticas, podese verificar como esse campo de estudo está constituído e interagindo a partir das redes de coautoria, as limitações das investigações utilizando tais temáticas e quais outros aspectos estão sendo discutidos em âmbito nacional e internacional sobre a saúde mental de docentes préescolares. Quando estabelecidas as conexões dos termos, busca-se a compreensão das relações envolvendo conceitos e significados na construção e difusão de conhecimentos em estudos de Revisão da Literatura (SANTOS JÚNIOR, 2015). Consequentemente, esta pesquisa objetivou levantar dados a respeito da produção acadêmica sobre Estresse e Professores de Educação Infantil no período de 2008 a 2018, com enfoque em redes de termos e redes de coautoria.

\section{Método}

\subsection{Natureza da Pesquisa}

A investigação é de Natureza Aplicada, pois segundo Gil (2008) ela está interessada na aplicação prática dos conhecimentos originados referentes a locais específicos. Quando levantados os dados a respeito das publicações sobre Estresse e Professores de Educação Infantil, pretende-se a sua utilização para próximas pesquisas. Quanto à abordagem do problema é do tipo Quanti-qualitativa, porque além de trazer a análise de dados estatísticos, o fenômeno será interpretado para atribuição de significado ao mesmo tempo a partir de elementos textuais (KAUARK; MANHÃES; MEDEIROS, 2010). Quanto aos objetivos, o estudo possui caráter Exploratório e Descritivo, pois realizou levantamento bibliográfico e estabeleceu-se relações entre as variáveis escolhidas para estudo. Em relação aos procedimentos, é do tipo pesquisa bibliométrica.

A pesquisa bibliométrica possui relevância na análise da produção científica, pois por meio dela pode-se obter um panorama a respeito do desempenho das publicações sobre uma determinada área do conhecimento. Buscam-se com essa técnica as respostas considerando variáveis: pesquisadores/autores; instituições ou temas; tipos de pesquisa; objetivos das investigações, dentre outras (ARAÚJO; ALVARENGA, 2011).

Para Santos Junior et al. (2015), ao se observar um conceito, a posição, a importância e os significados de uma palavra dentro de um texto, leva-se em consideração o contexto textual no qual a palavra está inserida. Por isso, essa pesquisa examinou como variáveis os títulos e as palavras-chave dos artigos, a fim de verificar-se a existência de temáticas em comum nos estudos, pesquisando as conexões que possa haver entre elas. 


\subsection{Delimitação das fontes e Procedimentos de coleta}

Primeiramente foram definidos os descritores das temáticas que seriam pesquisados. Eles foram divididos em duas categorias: (1) Estresse (Stress), (2) Professores de Educação Infantil (Kindergarten Teachers), tanto em português como em inglês, os quais foram pesquisados de forma isolada e por cruzamentos entre eles e seus sinônimos nos referidos diretórios (Quadro1). Procurou-se realizar um levantamento da literatura, por meio de buscas por pesquisas empíricas nos diretórios da Coordenação de Aperfeiçoamento de Pessoal de Nível Superior (CAPES), Literatura Latino Americana e do Caribe em Ciências da Saúde (LILACS), Scientific Eletronic Library Online (SCIELO) e Education Resources InformationCenter(ERIC).

Quadro 1 - Palavras-chave em português e inglês utilizadas para busca de artigos sobre Estresse em Professores de Educação Infantil, nos diretórios de pesquisa da CAPES, LILACS, SCIELO E ERIC, no período de 2008 a 2018

\begin{tabular}{|l|l|}
\hline \multicolumn{2}{|c|}{ Descritores (em português e inglês) } \\
\hline Estresse & $\begin{array}{l}\text { Professores de Educação Infantil; Professores } \\
\text { Pré-escolares }\end{array}$ \\
\hline Stress & Kindergarten teachers; Preschool teachers \\
\hline \multicolumn{2}{|c|}{ Cruzamentos realizados para buscas nas bases de dados (em português e inglês) } \\
\hline Estresse x Professores de Educação Infantil & Stress x Kindergarten Teachers \\
\hline Estresse x Professores pré-escolares & Stress x Preschool teachers \\
\hline
\end{tabular}

Fonte: Elaborado pelas Autoras (2019).

Os parâmetros de inclusão para a escolha dos artigos atenderam aos seguintes critérios: (1) Publicados nos últimos 10 anos; (2)Somente artigos; (3) em Português e Inglês; (4) Com descritor principal no título ou palavras-chave; (5) Disponível gratuitamente; (6) Na íntegra; (7) Revisado por pares e (8) Que se referissem a Professores. Os artigos que não obedeceram a esses critérios de inclusão foram automaticamente descartados.

Para obtenção de informações, utilizou-se de técnicas de coleta de Pesquisa Bibliométrica, pois, como já mencionado, as fontes foram artigos científicos. Esses foram lidos e algumas variáveis foram extraídas para análise: a) autores e coautores; b) palavras- chave; c) qualis das revistas e d) tipo de pesquisa.

\subsection{Análise dos dados}

Para análise dos dados, utilizou-se estatística descritiva, com resultados organizados cuidadosamente em forma de tabelas ou gráficos para os dados quantitativos, que permitiram a elaboração de um resumo e descrição das características dos dados apresentados (GUIMARÃES, 2008). Para as informações textuais, aplicou-se análise de rede semântica com auxílio da Teoria dos Grafos. As categorias coletadas foram inseridas na ferramenta Microsoft Excel e executadas no software NodeXL para obtenção dos escores, análise das métricas e construção dos grafos resultantes.

As Métricas são medidas matemáticas que geram e ajudam a descrever os Grafos, e ambos são ferramentas oriundas da Teoria dos Grafos, que, segundo Higgins e Ribeiro (2018) e Ramos (2015), correspondem a um tipo de geometria, conhecida de forma específica como topologia para estudar relações entre objetos e que vem ganhando expansão devido a diversos 
usos aplicados. O Quadro 2 apresenta um resumo das principais métricas utilizadas e seus conceitos para análise de redes.

Quadro 2 - As métricas mais utilizadas em Análise de Redes e seus conceitos.

\begin{tabular}{|l|l|}
\hline \multicolumn{1}{|c|}{ Métricas } & \multicolumn{1}{c|}{ Conceito } \\
\hline \multirow{5}{*}{ Degree } & $\begin{array}{l}\text { Grau de centralidade, que corresponde ao número de arestas que incidem em } \\
\text { determinado vértice. Se o grafo for orientado por setas, a métrica pode ser de dois } \\
\text { tipos: }\end{array}$ \\
\cline { 2 - 3 } & In Degree, corresponde ao número de arestas que um vértice recebe. \\
\cline { 2 - 3 } & Out Degree, implica no número de arestas que saem de um vértice. \\
\hline Betweenness & $\begin{array}{l}\text { Calcula a importância de intermediação de um nó na rede, considerando as perdas } \\
\text { ou não que a retirada deste possa causar a rede. }\end{array}$ \\
\hline Closentrality & $\begin{array}{l}\text { Verifica a proximidade entre dois vértices na rede, assumindo o menor valor possível } \\
\text { de 1 (distância geodésica), ou seja, a menor distância entre dois nós. }\end{array}$ \\
\hline Eigenvector \\
Centrality & $\begin{array}{l}\text { Calcula o grau de relevância do nó na rede, tendo como referência valores que } \\
\text { variam entre 0 (menor relevância) e 1 (maior relevância). }\end{array}$ \\
\hline \multirow{2}{*}{ Page Rank } & $\begin{array}{l}\text { Calculada somente em grafos direcionados, é uma métrica que também aponta a } \\
\text { importância do nó na rede, mostrando o quanto esta está ligada aos demais vértices } \\
\text { que compõem a rede. }\end{array}$ \\
\hline
\end{tabular}

Fonte: Adaptado de Hansen, Shneiderman, Smith (2011) e Ramos (2015).

$\mathrm{Na}$ atualidade, as métricas podem ser aplicadas em técnicas de análises de redes sociais, redes semânticas ou mesmo em análise de termos-chave e coautoria, como é o caso da pesquisa em questão.

\section{Resultados e Discussão}

Após as buscas realizadas nos quatro diretórios com descritores de forma isolada e por cruzamentos, aplicou-se os critérios de inclusão que resultaram em 52 artigos, que foram lidos e avaliados. A Tabela 1 apresenta o resumo do número de artigos resultantes da busca em cada base de dados.

Tabela 1 - Resultado detalhado da quantidade de artigos sobre Estresse e Professores da Educação Infantil encontrados nas bases de dados CAPES, LILACS, SCIELO, ERIC, Brasil, no período de 2008 a 2018.

\begin{tabular}{lcllll}
\hline \multicolumn{5}{c}{ ARTIGOS ENCONTRADOS POR DIRETÓRIOS DE PESQUISA } \\
\hline DIRETÓRIOS & $\begin{array}{l}\text { Artigos } \\
\text { Busca inicial de } \\
\text { artigos }\end{array}$ & $\begin{array}{l}\text { Artigos } \\
\text { selecionados após } \\
\text { aplicação dos } \\
\text { rritérios }\end{array}$ & $\begin{array}{l}\text { Pesquisas } \\
\text { nacionais }\end{array}$ & $\begin{array}{l}\text { Pesquisas } \\
\text { internacionai } \\
\text { ses }\end{array}$ \\
\hline CAPES & 9 & 8 & & \\
LILACS & 14 & 5 & 17 & 23 & 12 \\
SCIELO & 13 & 10 & & \\
ERIC & 16 & 12 & & \\
Total & 52 & 35 & & \\
\hline
\end{tabular}

Fonte: Elaborada pelas Autoras (2019)

Como apresentado, dos 52 artigos encontrados, 17 eram artigos repetidos, o que indica a submissão simultânea do mesmo trabalho em revistas diferentes, haja vista o demorado processo para publicação. Após a leitura dos objetivos e metodologias de cada trabalho, chegouse à conclusão de que somente 35 correspondiam a temática da pesquisa. Dentre este total, 23 são pesquisas nacionais e 12, pesquisas internacionais. Como acompanhado no Gráfico 1, o tipo 
de pesquisa mais empregado foi a de abordagem qualitativa, sendo percebida em 15 artigos (43\%), seguida da abordagem quantitativa, empregada em 13 artigos (37\%) e a menos utilizada foi a abordagem mista, encontrada em 7 artigos (20\%).

Gráfico 1 - Porcentagem dos tipos de pesquisa mais utilizados nas metodologias dos artigos sobre Estresse e Professores da Educação Infantil, levantados nos diretórios da CAPES, LILACS, SCIELO e ERIC, no período de 2008 a 2018.

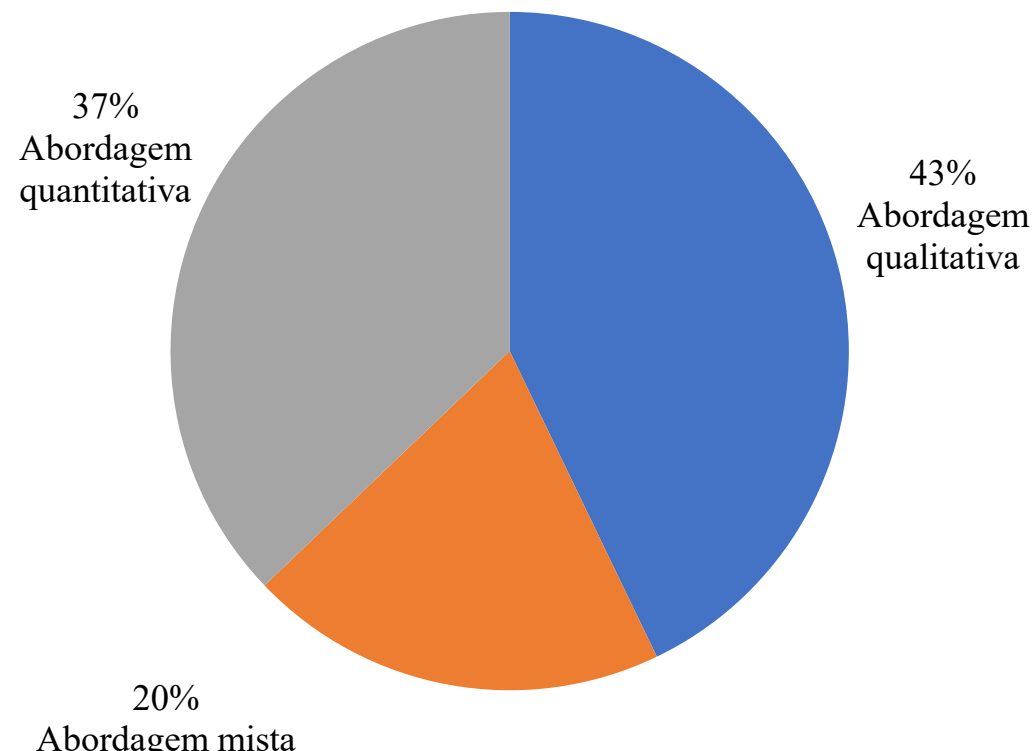

Fonte: Elaborado pelas Autoras (2019).

Outra característica do conjunto de artigos encontrados é a avaliação das revistas nas quais foram publicados. Essa classificação é feita pela Qualis-Periódicos, sistema pertencente à CAPES, para identificar a qualidade da produção científica da pós-graduação, por meio da avaliação dos periódicos em que são publicados. Cada revista precisa obedecer a critérios definidos por comitês de consultores de cada área em avaliação que classificam as revistas em uma das 8 categorias, de acordo com a soma dos critérios estipulados. Sendo assim, para ser classificada como A1 e A2, a revista precisa alcançar as pontuações 100 e 85, respectivamente, para serem consideradas revistas de alta qualidade; para as classificações B1 e B2, e serem considerados periódicos de boa qualidade, precisam obter os valores 70 e 55 pontos. Revistas com Qualis B3, B4, B5 e C pontuam, respectivamente, 40, 25, 10 e 0, as quais são consideradas de baixa qualidade. O Gráfico 2 apresenta o Qualis dos periódicos dos artigos encontrados nesta investigação. 
Gráfico 2 - Quantidade de artigos sobre Estresse e Professores da Educação Infantil e a classificação Qualis dos periódicos nos quais foram publicados, no período de 2008 a 2018.

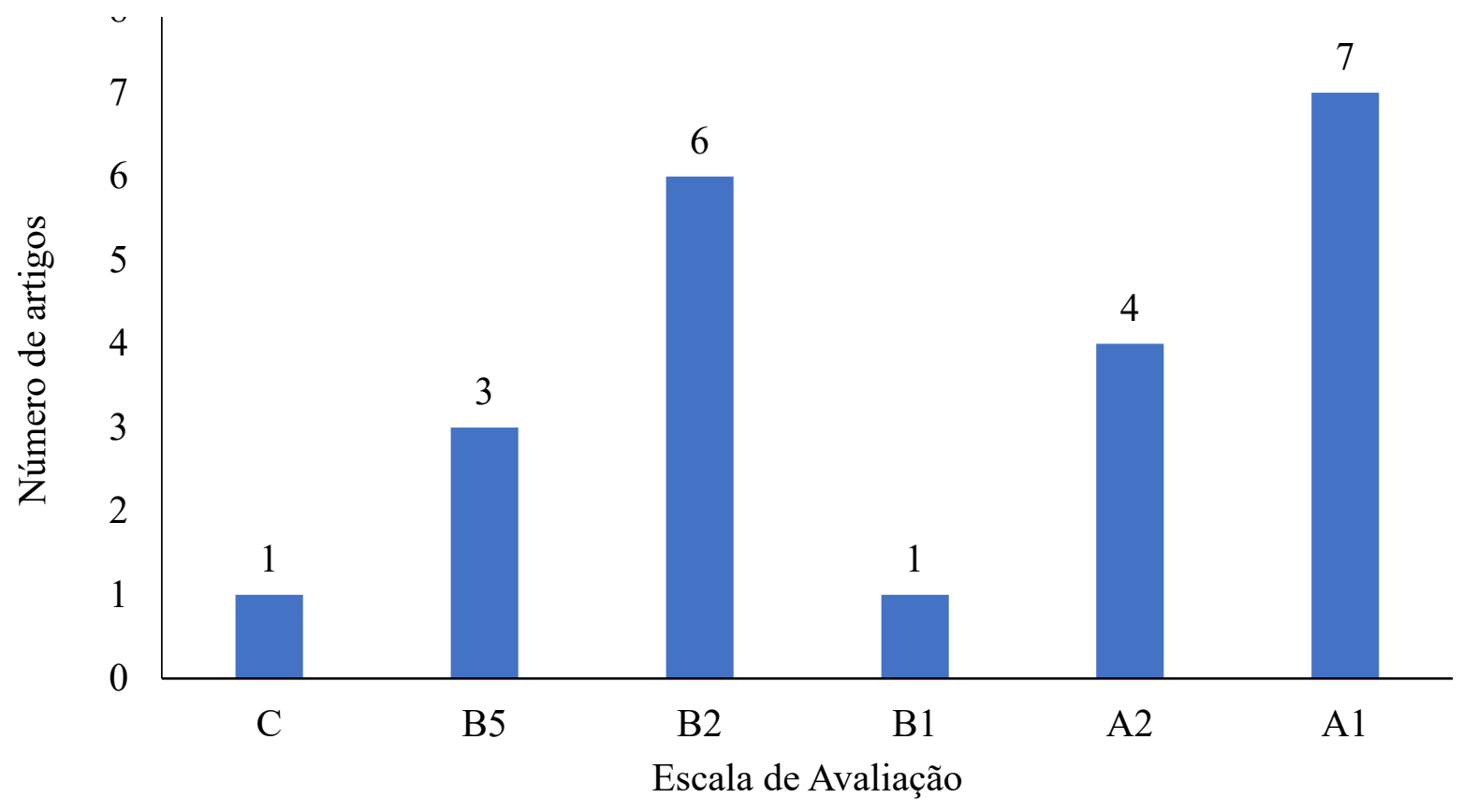

Fonte: Elaborado pelas Autoras (2019).

Dos periódicos em que os estudos foram publicados, existem 13 que não possuem classificação no site da Capes. Os demais periódicos aos quais pertencem os artigos achados neste estudo a avaliação Qualis tem a seguinte distribuição: A1: 7 revistas; A2: 4 revistas; B1: 1; B2: 6 revistas; B5: 3 revistas e C: 1 revistas.

\subsection{Análise de redes de termos-chave e coocorrências de autorias}

Para visualização das relações entre as variáveis levantadas nos estudos, aplicou-se um estudo das redes de termos-chave e das parcerias entre autores (co-autoria), com apoio das ferramentas Nodexl e Microsoft Excel. O Nodexl é uma ferramenta que possui linguagem computacional e matemática para observar as conexões entre objetos em estudo, visualizados em Grafos (RAMOS, 2015). Ainda segundo a autora, os grafos correspondem a visualização da aplicação da técnica para análise dos resultados, que são representados por meio de diagramas. Nestes as relações são constituídas por linhas (arestas) e os pontos (vértices) que são os objetos que estabelecem conexões. Neste estudo, utilizaram-se as seguintes variáveis: autores e coautores e palavras-chave. A estas foram aplicadas métricas para que se percebessem nestas relações as medidas de centralidade, intermediação e importância.

\subsection{Rede de coocorrência de autorias}

A constatação da relevância de um vértice em uma rede social pode ser feita com auxílio da técnica de Análise de Redes. Por meio desta, é possível estabelecer o caráter que determinado ator possui na estrutura de uma rede, identificando a sua posição de poder ou centralidade. Quando o autor é central na rede, isso corresponde a mais aberturas para relações de trocas e comunicações e menos ressalvas, o que lhe proporciona poder nas relações (MAIA; CAREGNATO, 2008). A seguir apresenta-se a Tabela 2, que representa os escores para a métrica Eigenvector Centrality, e Grafo 1 (Figura 1), a representação estrutural das relações 
com maior e menor importância na rede, respectivamente.

Tabela 2- Valores obtidos por cada autor para a métrica Eigenvector Centrality, suas parcerias, seu papel na rede e o número de artigos sobre Estresse e Professores da Educação Infantil que publicou em parcerias, no período de 2008 a 2018 (Continua)

\begin{tabular}{|c|c|c|c|c|}
\hline Autores e coautores & $\begin{array}{l}\text { Eigenvector } \\
\text { Centrality }\end{array}$ & Parceria & $\begin{array}{c}\text { Forma de associação } \\
\text { In degree }(\hookrightarrow) \\
\text { Out degree }(\leftrightarrow) \\
\text { In/Out degree }(\leftrightarrow)\end{array}$ & $\begin{array}{l}\text { Número de } \\
\text { artigos que } \\
\text { indica a } \\
\text { coautoria }\end{array}$ \\
\hline \multirow{9}{*}{ SILVA } & \multirow{9}{*}{0,146} & Lima & & 2 \\
\hline & & Rocha & & 1 \\
\hline & & Filho & & 1 \\
\hline & & Boscari & & 1 \\
\hline & & Amer & & 1 \\
\hline & & Almeida & & 1 \\
\hline & & Fernandes & & 1 \\
\hline & & Chiaparini & & 1 \\
\hline & & Cunha & & 1 \\
\hline \multirow{6}{*}{ ROCHA } & \multirow{6}{*}{0,128} & Filho & & 1 \\
\hline & & Silva & & 1 \\
\hline & & Boscari & & 1 \\
\hline & & Amer & & 1 \\
\hline & & Almeida & & 1 \\
\hline & & Buss-Simão & & 1 \\
\hline \multirow{6}{*}{ FILHO } & \multirow{6}{*}{0,124} & Rocha & & 1 \\
\hline & & & = & \\
\hline & & Silva & & 1 \\
\hline & & Boscari & & 1 \\
\hline & & Amer & & 1 \\
\hline & & Almeida & & 1 \\
\hline
\end{tabular}


Tabela 2 - Valores obtidos por cada autor para a métrica Eigenvector Centrality, suas parcerias, seu papel na rede e o número de artigos sobre Estresse e Professores da Educação Infantil que publicou em parcerias, no período de 2008 a 2018 (Continua)

\begin{tabular}{|c|c|c|c|c|}
\hline Autores e coautores & $\begin{array}{r}\text { Eigenvector } \\
\text { Centrality }\end{array}$ & Parceria & $\begin{array}{l}\text { Forma de associação } \\
\text { In degree ( } \\
\text { Out degree (a) } \\
\text { In/Out degree }\end{array}$ & $\begin{array}{r}\text { Número de } \\
\text { artigos que } \\
\text { indica a } \\
\text { coautoria }\end{array}$ \\
\hline \multirow{6}{*}{ BOSCARI } & \multirow{6}{*}{0,124} & Rocha & 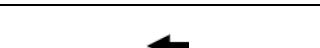 & 1 \\
\hline & & Filho & & 1 \\
\hline & & & $\leftarrow$ & \\
\hline & & Silva & & 1 \\
\hline & & Amer & & 1 \\
\hline & & Almeida & & 1 \\
\hline \multirow{7}{*}{ AMER } & \multirow{7}{*}{0,124} & Rocha & & 1 \\
\hline & & & $<$ & \\
\hline & & $\overline{\text { Silva }}$ & 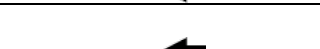 & 1 \\
\hline & & & & \\
\hline & & Filho & 4 & 1 \\
\hline & & Boscari & & 1 \\
\hline & & Almeida & & 1 \\
\hline \multirow{6}{*}{ ALMEIDA } & \multirow{6}{*}{0,124} & Rocha & 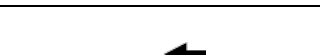 & 1 \\
\hline & & Filho & & 1 \\
\hline & & & $<$ & \\
\hline & & Silva & 4 & 1 \\
\hline & & Boscari & & 1 \\
\hline & & Amer & & 1 \\
\hline
\end{tabular}

Fonte: Elaborado pelas Autoras (2019).

O ponto de corte para escolha dos termos obedeceu aos escores que possuíam valores $\geq 0,124$ na métrica Eigenvector Centrality, que corresponde à importância do vértice na rede e é calculada por meio da variação dos valores entre 0 e 1 . Quanto mais próximo de zero for o valor, menos relevante é o vértice, do contrário, quanto mais próximo de 1 estiver o valor, mais importância possui este vértice. Sendo assim, os autores que pontuaram com escores entre 0,146 e 0,124 são os que representam maior relevância nos estudos a respeito das temáticas Estresse e Professores de Educação Infantil, mesmo que esses valores estejam muito próximos a zero. A representação estrutural pode ser percebida com a observação da Figura 1. 
Estresse em professores de educação infantil: um estudo bibliométrico

Figura 1 - Multigrafo das relações entre coautores e autores de artigos sobre Estresse de Professores da Educação Infantil, que possuem maior e menor importância na rede, no período de 2008 a 2018.
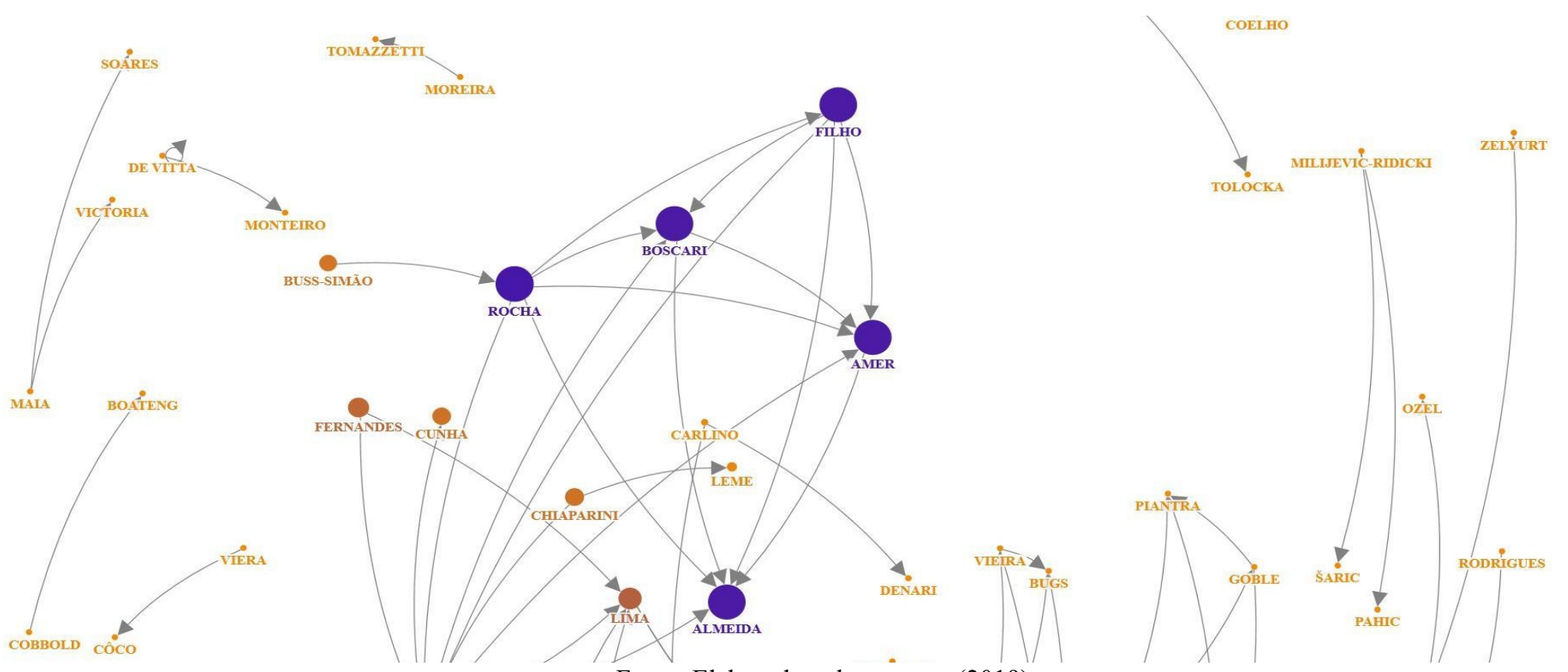

Fonte: Elaborado pelas autoras (2019)
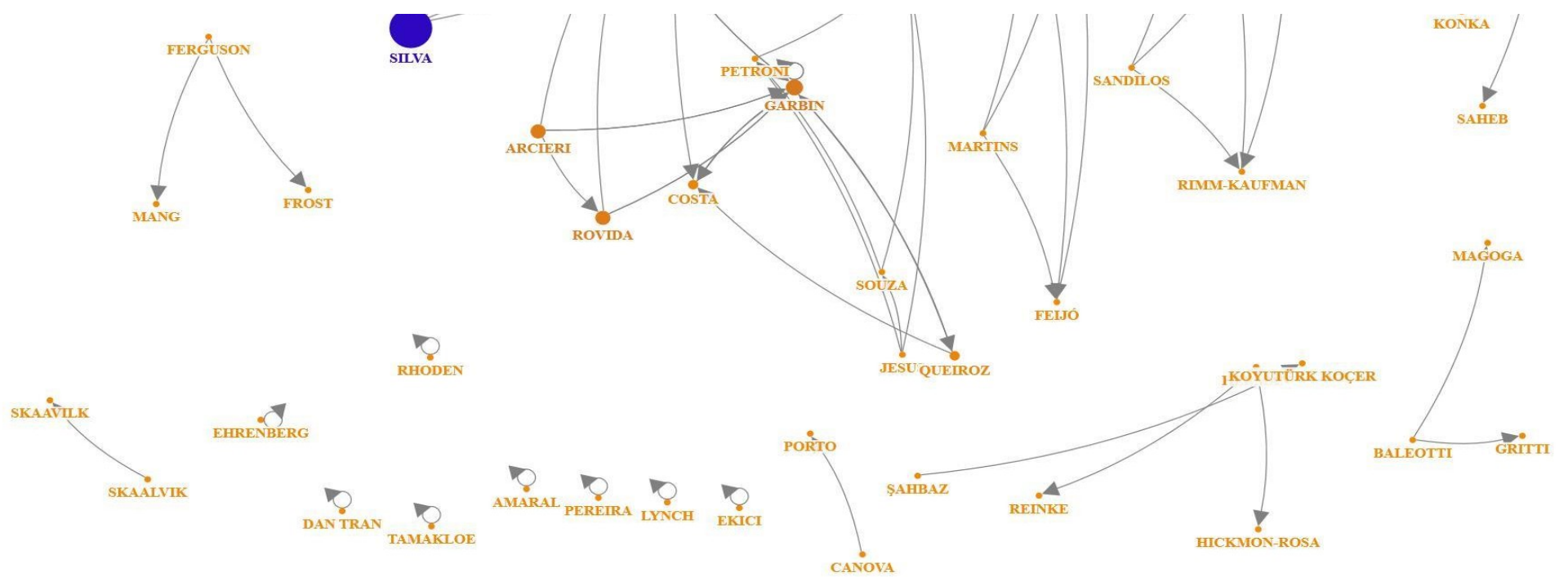
Podem-se perceber seis vértices (nós) que estão em destaque pelo tamanho e cor azul e correspondem aos maiores valores encontrados para a métrica aplicada. Os demais vértices com tamanho menor e cor alaranjada correspondem a autores que possuem escores menores que 0,124 ou não pontuaram nesta métrica. Quanto maior for a esfera, mais elevado é o escore do vértice na métrica de corte escolhida, e mais destaque possui o autor por suas publicações em parceria. Vale ressaltar que mesmo que os autores em evidência no vértice assumam destaque estrutural, do ponto de vista dos valores obtidos na métrica, percebe-se que estes ainda não possuem notoriedade, pois os escores estão distantes de um. No entanto, as poucas conexões entre autores já indicam o início para este novo caminho a ser investigado.

Os seis vértices em maior evidência correspondem a um grupo específico de autores "Rocha, Filho, Silva, Boscari, Amer e Almeida (2017)" que publicaram um trabalho em conjunto. Estes possuem interações com outros grupos, por meio de relações que são orientadas, ou seja, as setas indicam que se estabeleceram parcerias entre "Buss-Simão e Rocha (2018)", "Fernandes, Lima e Silva (2017)", "Silva e Cunha (2016)", "Silva e Lima (2014)", "Chiaparini, Silva e Leme (2018)" para publicar.

No estudo do grupo em destaque, os autores analisaram a relação do estresse com sintomas osteomusculares em docentes da educação básica. A pesquisa mostrou que $48 \%$ dos professores apresentam tais sintomas físicos em diferentes partes do corpo: joelhos (67\%), tornozelo/pés (61\%) e pescoço (57\%). Quanto aos sintomas de estresse, verificou-se que $42 \%$ dos participantes se encontravam em algum nível de estresse, com a incidência dos sintomas psicológicos sobre os físicos. Apesar de esses percentuais elevados apontarem para um quadro de doença, a pesquisa concluiu que esse quadro não implica na qualidade de vida dos professores do estudo, pois esses alegaram que suas relações sociais e sentimentais não são tão afetadas quando comparadas a questões físicas e do meio ambiente, as quais não conseguem administrar (ROCHA et al.,2017).

Sobre as parcerias, percebe-se que duas destas possuem trabalhos com o objetivo de apresentar a formação do futuro professor da Educação Infantil, suas características, peculiaridades e fragilidades. Além disso, ambas as pesquisas mostram a necessidade de investimento na formação e valorização do profissional, visando a contribuição na construção de sua identidade (CHIAPARINI; SILVA; LEME, 2018; BUSS-SIMÃO; ROCHA,2018).

Em outras parcerias (FERNANDES; LIMA; SILVA, 2017; SILVA; CUNHA, 2016), os autores enfatizam a respeito da ausência de encontros formativos adequados, pois esses poderiam contribuir com a compreensão e atuação dos profissionais frente a temas como Meio Ambiente (SILVA; CUNHA, 2016) e interdisciplinaridade da Educação Infantil, aproximando outras áreas como a da saúde com a do trabalho pedagógico, visando qualidade de vida do indivíduo. Na parceria de Silva e Lima (2014), a ênfase é dada para os benefícios sociais da prática de inclusão iniciados com crianças na idade da Educação Infantil.

Além desses, há grupos como os de "Tomazzetti e Moreira (2018)" e "Ferguson, Mang e Frost (2017)", por exemplo, que compartilharam a autoria de trabalhos, mas não possuem elevados escores de centralidade e não se conectam com os demais grupos. Isso pode ser explicado pelo fato de alguns pesquisadores estarem preocupados com temáticas voltadas a saúde do professor, levantando dados sobre o estresse da profissão, sua repercussão e falta de apoio no ambiente de trabalho, desvinculando-se da temática sobre formação do profissional (FERGUSON; MANG; FROST, 2017). Outros estudiosos investigaram a necessidade de outras questões, como a avaliação na Educação Infantil, serem abordadas em encontros de professores, com objetivo de atualizá-los, sendo essa uma proposta para o surgimento de novas parcerias (TOMAZZETTI; MOREIRA,2018).

Existem também os autores que não compartilharam a autoria de seus trabalhos com outros coautores e, portanto, aparecem sem conexão na rede. Esses discutem a respeito da formação de qualidade que deve ter os professores para atuar na Educação Infantil, ofertada 
tanto a nível profissional (AMARAL, 2011) como continuada, no exercício da profissão (PEREIRA, 2017).

Em síntese, a estrutura da rede de coautoria revela que os autores destacados não concentram muitas publicações em conjunto quando se observa o número de autores disponível para tais parcerias, e talvez isso indique o motivo das pesquisas envolvendo os termos Estresse e Educação Infantil ainda não ganharem difusão. Ainda assim, as poucas parcerias possuem tímidas publicações, mas que já caracterizam o início de novas possibilidades envolvendo as áreas da saúde e da educação.

\subsection{Análise de conexões de termos-chave}

No estudo das relações entre as palavras-chave, utilizou-se como ponto de corte valores que apresentaram escores $\geq 0,024$, também na métrica Eigenvector Centrality, como já apresentada, trata-se de uma medida utilizada para evidenciar a importância do nó na rede, tendo como parâmetros valores entre 0 e 1 para destacar menor relevância ou maior relevância, respectivamente. Os resultados indicaram que na medida sobre importância do vértice as palavras que apresentaram maiores escores variaram entre 0,024 e 0,111 . É perceptível o destaque nos valores entre as palavras, pois a palavra- chave "educação infantil" tem um escore bem mais elevado quando comparado aos valores das demais. Na Tabela 3, dá-se a melhor visualização para esta comparação.

Tabela 3 - Apresentação decrescente dos escores obtidos com a métrica Eigenvector Centrality para apontar as palavras-chave com maior destaque nos estudos sobre Estresse e Professores de Educação Infantil, encontrados nos diretórios CAPES, LILACS, SCIELO e ERIC, no período de 2008 a 2018.

Palavras-chave

Eigenvector Centrality

\begin{tabular}{ll}
\hline Educação infantil & 0,111 \\
\hline Formação de professores & 0,039 \\
\hline Condição humana & 0,026 \\
\hline Fragmentação & 0,026 \\
\hline Diferentes linguagens & 0,026 \\
\hline Edgar Morin & 0,026 \\
\hline Deficiência & 0,026 \\
\hline Inclusão social & 0,026 \\
\hline Cuidado & 0,026 \\
\hline Práticas corporais & 0,026 \\
\hline Meio ambiente & 0,026 \\
\hline Representação social & 0,026 \\
\hline Ensino de ciências & 0,026 \\
\hline Prática pedagógica & 0,026 \\
\hline Educação especial & 0,024 \\
\hline Necessidades educacionais especiais & 0,024 \\
\hline Violência doméstica & 0,024 \\
\hline Infância & 0,024 \\
\hline
\end{tabular}

Fonte: Elaborado pelas Autoras (2019). 
Na Tabela 3, percebe-se que o termo "educação infantil" possui maior importância na rede, por apresentar um vértice com tamanho e cor destacados dos demais, já que seu escore resultante foi 0,111 . Isso pode ser explicado, pois se trata de uma palavra-chave que foi utilizada como descritor principal de busca, sendo esperada a evidência desse termo. Ainda assim, a topografia (Figura 2) indica o destaque da palavra, mas o escore obtido ainda está longe do valor que caracteriza importância. Os vértices que representam palavras que possuem tamanhos médios com cores escuras também indicam os temas que aparecem com relevância nos estudos, com escores que variam entre 0,024 a 0,039 . Já os vértices pequenos possuem escores inferiores a 0,024 , aparecem nos estudos, mas estão pouco conectados nas pesquisas sobre as temáticas. 
Figura 2 - Conexões entre termos-chave referentes às temáticas dos artigos sobre Estresse e Professores de Educação Infantil, no período de 2008 a 2018

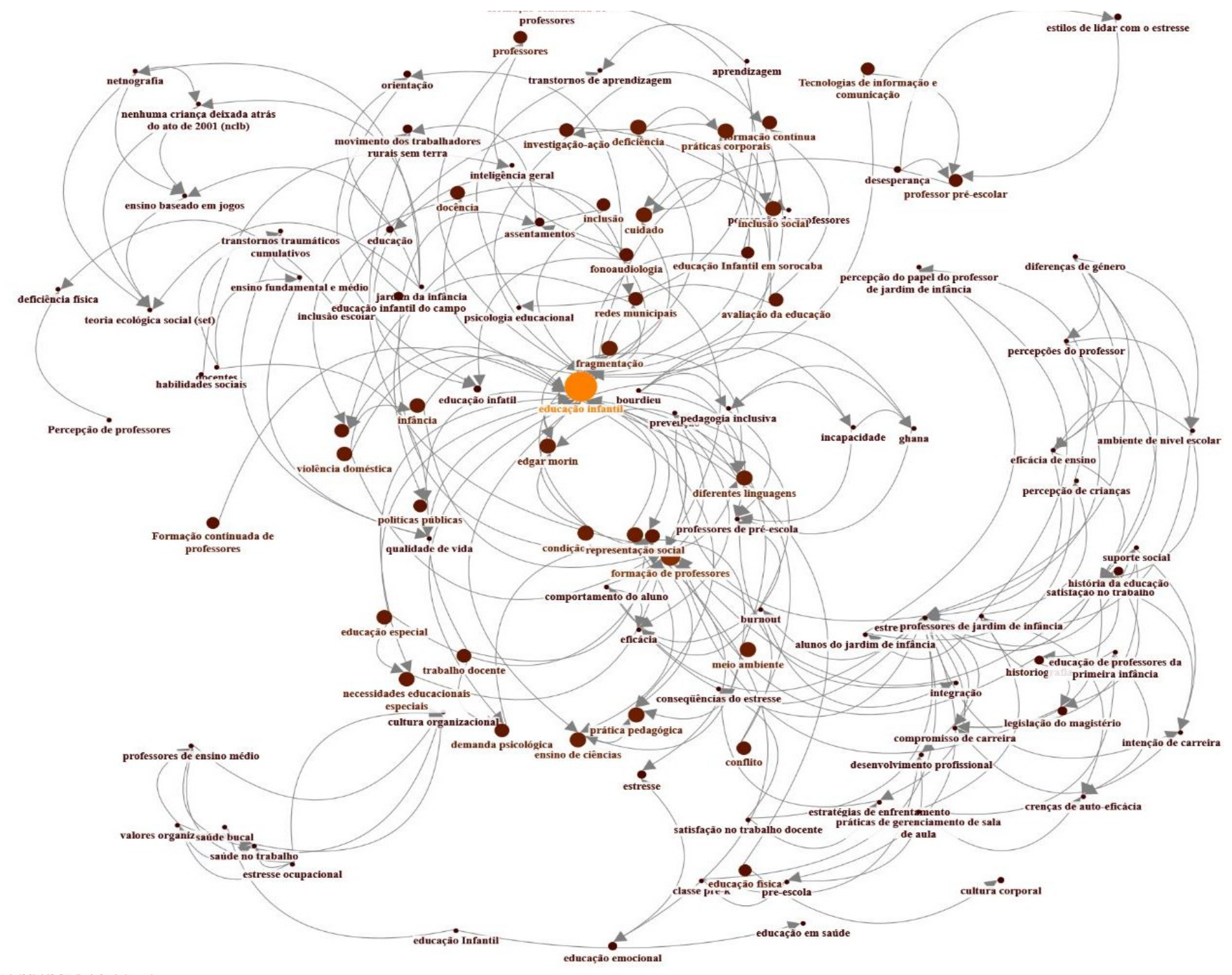

Fonte: Elaborado pelas autoras (2019). 
O nó "educação infantil" apresenta arestas em dois sentidos, que representam a influência do vértice, com a sua direção ressaltada por setas direcionadas. As setas que incidem no vértice indicam a influência que ele está sofrendo de outros vértices e pode ser analisada por meio da medida in degree. Há também setas que saem do nó principal em direção a outros nós, mostrando a influência que têm sobre eles, ponderada pela métrica out degree. A Figura 3 mostra, por meio de uma nuvem de palavras, os termos-chave que mais foram publicados em associação ao termo principal "educação infantil".

Figura 3 - Nuvem de palavras dos termos-chave relacionados à “educação infantil”, nos artigos sobre Estresse e Professores de Educação Infantil, no período de 2008 a 2018

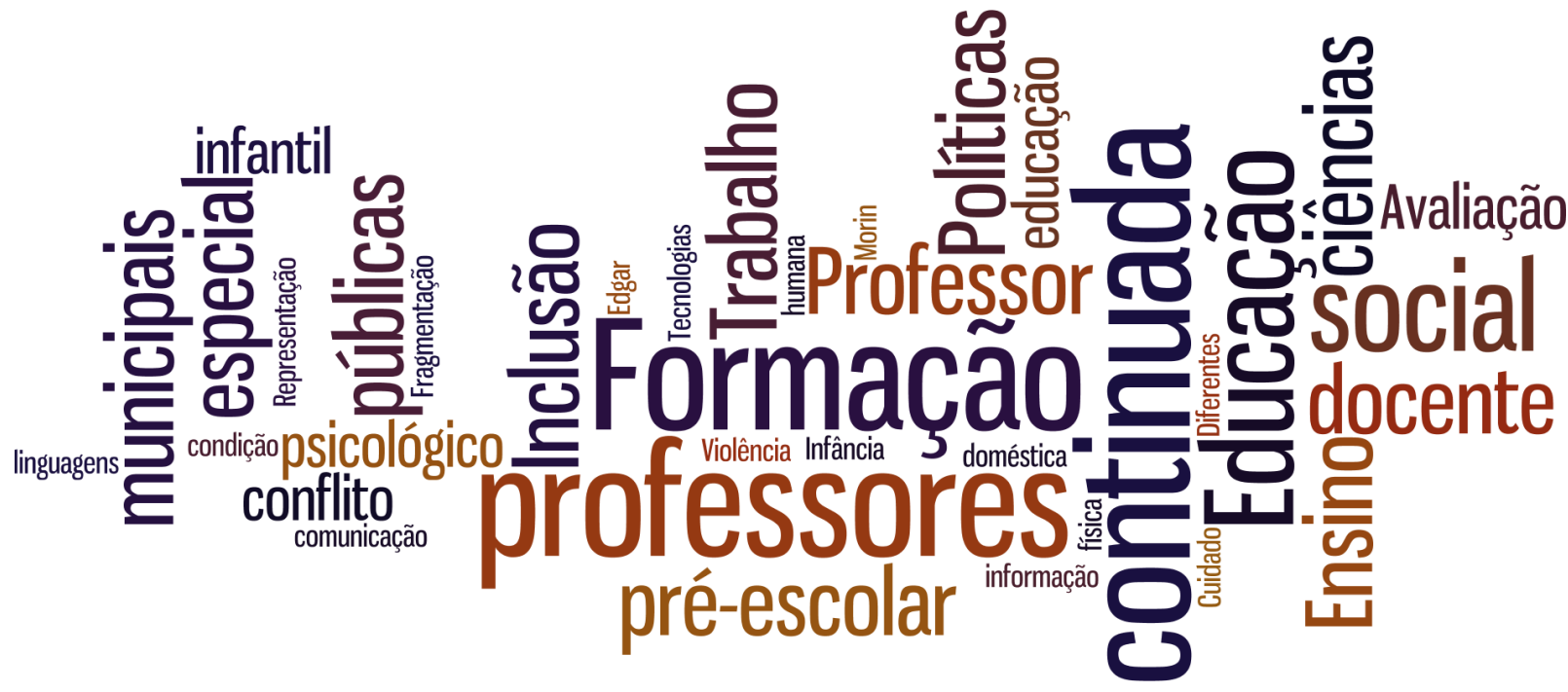

Fonte: Elaborado pelas Autoras (2019).

As palavras apresentam tamanhos diferentes, pois sua incidência nos artigos possui frequências diferentes, portanto, quanto maior estiver a palavra, mais frequente/incidente ela é nos artigos investigados, sendo as mais notórias: formação continuada de professores $(\mathrm{f}=5)$; professor pré-escolar $(\mathrm{f}=3)$; inclusão social $(\mathrm{f}=3)$; educação especial $(\mathrm{f}=3)$; trabalho docente $(\mathrm{f}=3)$; Políticas públicas municipais $(\mathrm{f}=3)$; Ensino de ciências $(\mathrm{f}=2)$; avaliação na educação infantil ( $\mathrm{f}=2)$; conflito psicológico $(\mathrm{f}=2)$. As demais expressões aparecem uma única vez por estudo, tais como: Edgar Morin, violência doméstica, diferentes linguagens, fragmentação, dentre outras. As pesquisas que mostram a associação dos termos-chave ainda se encontram em estágio inicial, porém são um marco para investigações nesses campos.

Levando em consideração as direções das setas que incidem sobre o vértice, percebese que as palavras-chave "cuidado, inclusão, prática corporal, Edgar Morin, representação social, formação de professores, prática pedagógica, ensino de ciências, necessidades educacionais, condição humana" são termos ligadas ao vértice "educação infantil" com maior importância e estabelecem coocorrências nos artigos investigados.

Tal fato pode ser comprovado nas relações que trazem os estudos que abordam a prática dos professores de educação infantil frente aos desafios da educação especial (CARVALHO; COELHO; TOLOCKA, 2016), sobre a necessidade de se romper com o exacerbado tradicionalismo com crianças pequenas, fazendo-as refletir a respeito do seu espaço como indivíduo (RODRIGUES; SAHEB, 2015), além de trazer a formação contínua de qualidade para o docente como fortalecedora de sua prática interdisciplinar (SILVA; CUNHA, 2016). 
Ao se observar sobre a influência do descritor "educação infantil", percebe-se que o termo também se conectou às palavras-chave "infância, violência doméstica, educação especial, meio ambiente" estabelecendo ocorrência conjunta.

Essa influência pode ser evidenciada quando os resultados das investigações trazem a importância do aprimoramento dos professores atuantes na primeira infância, com a finalidade de preparo para compreender e lidar com situações ainda pouco palpáveis pelos docentes, como a violência familiar sofrida pelas crianças (GARBIN et al., 2010). Este assunto tem se expandido, chegando à sala de aula, necessitando que professores possam estar cada vez mais preparados para atuar ao perceberem situações de violência sofrida pelos alunos. Essas situações exigem que os professores assumam papéis além daqueles que lhes são solicitados na sala de aula, o que pode trazer situações desagradáveis, implicando em sua saúde mental.

A pesquisa de De Vitta, De Vitta e Monteiro (2010) destaca que uma prática efetiva na Educação Infantil demanda o conhecimento e o respeito às necessidades das crianças, especialmente se tratando das crianças com deficiências, que, segundo as informações, são pouco compreendidas pelos educadores. Outra relação que parece não ser característica da Educação Infantil é a que essa detém com o termo ensino de ciências. O estudo de Silva e Cunha (2016) indica que a formação específica para o ensino de ciências é necessária para que as crianças se aproximem de práticas de interação com o meio ambiente. No entanto, os professores que precisam participar dessas formações não dispõem de tempo livre, pois possuem um regime de trabalho integral, outra situação que pode implicar na qualidade do ensino e na saúde do professor.

Sendo assim, observa-se que o tema "educação infantil" tem conexões com diferentes áreas e temas, mas ainda são necessárias novas aproximações para que assuntos que relacionem professores de educação infantil e saúde docente possam ser cada vez mais investigadas.

\section{Considerações Finais}

Com a utilização da técnica de Análise de Redes de termos chave e coautoria, pode-se vislumbrar um panorama dos últimos 10 anos a respeito das pesquisas publicadas sobre Estresse em professores de Educação Infantil. Por meio da técnica de visualização de grafos e escores, identificou-se como estão as publicações científicas que abordam as áreas da saúde e da educação, mais precisamente na área da Educação Infantil e do estresse docente. A rede de coautoria indica um ligeiro crescimento das principais parcerias entre os autores, na qual um grupo tem maior relevância nos estudos, estabelecendo poucas conexões com outros pesquisadores. Quanto à rede de termos, constatou-se que o descritor principal foi: "educação infantil", termo intencionalmente utilizado na busca, que estabeleceu conexões com muitas outras variáveis - tais como "violência doméstica", "meio ambiente", "deficiência" - que possuem alta e baixa relevância na rede. Mesmo que as estruturas indiquem a importância de termos e autores e coautores, os resultados das métricas se distanciam de 1, o que faz-se refletir que ainda são necessários estudos para que pesquisas sobre saúde e educação se desenvolvam, e mais pesquisadores estabeleçam parcerias.

Um grupo de pesquisadores que estabelece maior número de conexões é o que possui maior importância na rede investigada, pois estabelecem conexões com outros pesquisadores de temas relacionados ou não à temática do Estresse em professores de Educação Infantil. O estudo desse grupo em destaque refere-se à relação dos problemas de saúde física com sintomas de estresse em docentes da educação básica. Nas interrelações que estabelecem com pesquisadores parceiros, as temáticas dos estudos originadas de tais parcerias vão de estudos sobre a saúde mental à formação inicial e continuada do professor da Educação Infantil. Esses estudos e parcerias entre autores trazem, ainda timidamente, para discussão a relação que existe entre a prática docente e o estresse, que pode acarretar em sintomas físicos, como evidenciado 
no estudo.

Com relação às redes de temáticas, como já mencionado, o termo "educação infantil" se relaciona a uma porção de outras palavras que pertencem as mais distintas áreas. Algumas podem ser associadas ao termo-chave, como infância e educação especial, pois compõem assuntos pertinentes a essa área. Por outro lado, o termo violência doméstica está associado à área em destaque, pois a violência doméstica tem ganhado proporções e a identificação dos sinais pode ser feita em ambiente escolar, onde essas crianças podem sentir-se seguras. Essa é uma demanda com a qual o professor também precisa lidar, pois são assuntos extracurriculares, dos quais precisam estar a par, visto o número crescente de violência contra a criança, fazendo com que o professor assuma posturas que não lhes correspondem para atuar em prol dos seus alunos. Essas demandas extras podem acarretar o estresse do docente.

O termo ensino de ciências está timidamente relacionado à área da educação infantil, pois é uma área que está sendo incorporada às práticas dos professores, por meio de formações continuadas. A formação desses professores é polivalente, o que muitas vezes dificulta o conhecimento específico, por isso formações em serviço são necessárias para que novas práticas possam ganhar espaço no currículo da Educação Infantil. Entretanto, os professores não possuem tempo livre, pois sua jornada de trabalho é dupla, o que pode implicar no desgaste físico e mental.

No entanto, sugere-se que se amplie a rede de coautoria, para que os pesquisadores de temáticas em comum e até mesmo diferentes possam estreitar relações, levando ao aumento de produções científicas relevantes. Percebeu-se que alguns estudos não tiveram autoria compartilhada nem entre coautores de mesmo grupo, muito menos com os coautores de outras áreas. Outra sugestão seria a análise da rede do ponto de vista de outras métricas, que tragam diferentes visões sobre as conexões das relações ocorridas entre pesquisadores e as palavraschave de tais estudos.

\section{Referências}

AMARAL, S. R. R. do. A formação de professores para a educação infantil e anos iniciais do ensino fundamental: permanências e rupturas decorrentes das dinâmicas sociais e da legislação do magistério. Revista HISTEDBR On-line, n.43, p. 103-117, set.2011.

ARAÚJO, R. F.; ALVARENGA, L. A bibliometria na pesquisa científica da pós-graduação brasileira de 1987 a 2007. R. Eletr. Bibliotecon. Ci. Inf., v. 16, n. 31, p.51-70, 2011.

BRASIL. Lei no 9.394, de 20 de dezembro de1996. Estabelece as Diretrizes e Bases da Educação Nacional. Diário Oficial da União da República Federativa do Brasil, Brasília, DF, 23 dez. 1996.

BUSS-SIMÃO, M.; ROCHA, E. A. C. Docência na educação infantil: uma análise das redes municipais no contexto catarinense. Revista Brasileira de Educação. v. 23, e230021, 2018.

CARVAlHO, A. F.; COELHO, V. A. C.; TOLOCKA, R. E., Professores de educação infantil e temas sobre inclusão de crianças com deficiência no ensino regular. Educ. Pesqui., v. 42, n. 3, p. 713-726, jul./set. 2016.

CHIAPARINI, C.; SILVA, I. M. M.; LEME, M. I. da S. Conflitos interpessoais na educação infantil: o olhar de futuros professores e egressos. Psicologia Escolar e Educacional. v. 22, n. 3, set/dez.2018.

DE VITTA, F. C. F.; DE VITTA, A.; MONTEIRO, A. S. R. Percepção de professores de 
educação infantil sobre a inclusão da criança com deficiência. Rev. Bras. Ed. Esp., v.16, n.3, p.415-428, Set.-Dez., 2010.

FERGUSON, K.; MANG, C.; FROST, L., Teacher Stress and Social Support Usage. Brock Education Journal, v. 26, n. 2 2017. p. 62-83.

FERNANDES, D. M. Z.; LIMA, M. C. M. P.; SILVA, I. R. A percepção de professores de educação infantil sobre a atuação fonoaudiológica na escola. Distúrb. Comun, v. 29, n. 1, p. 86-96, março, 2017.

GARBIN, C. A. S.; QUEIROZ, A. P. D. de G. e; COSTA, A. A.; GARBIN, A. J. I. Formação e atitude dos professores de educação infantil sobre violência familiar contra criança. Educar em Revista, n. especial 2, p. 207-216, 2010.

GIL, A. C. Métodos e técnicas de pesquisa social. 6 ed. São Paulo: Atlas, 2008.

GUIMARÃES, P. R. B. Métodos Quantitativos Estatísticos: conceitos e aplicações Curitiba: IESDE Brasil S.A., 2008.

HANSEN, D. L.; SHNEIDERMAN, B.; SMITH, M. A. Social Media: New Technologies of Collaboration. In: Analyzing Social Media Networks with NodeXL. Morgan Kaufman (Elsevier): Burlington, Massachusetts, p. 11-29, 2011.

HIGGINS; S. S.; RIBEIRO, A. C. A. Análise de redes em Ciências Sociais. Brasília: Enap,2018.

JESUS, J. S. de; SOUZA, V. L. T. de; PETRONI, A. P.; DUGNANI, A. P. da C. Os sentidos da aprendizagem para professores da educação infantil, ensino fundamental e médio. Rev.

Psicopedagogia, v.30, n. 93, 201-11, 2013.

SANTOS JUNIOR, R. P. dos. et al. Análise de diferentes conceitos de educação por meio das redes semânticas. Revista de Informação, v.15, n.3, jun. 2015.

KAUARK, F.; MANHÃES, F. C.; MEDEIROS, C. H. Metodologia da pesquisa: guia prático. Itabuna: Via Litterarum, 2010.

KONCA, A.S., OZEL, E.; ZELYURT, H. Attitudes of preschool teachers toward susing information and communication technologies (ICT). International Journal of Research in Education and Science (IJRES), v. 2, n. 1, p. 10-15. 2016.

LYNCH, M. The Perspective of Kindergarten Teachers on Play in the Classroom. American Journal of Play, v. 7, n. 3, p.374-370. 2015.

MAIA, M. de S. F; CAREGNATO, S. E. Coautoria como indicador de redes de colaboração científica. Perspectivas em Ciência da Informação, v. 13, n.2, p.18-31, maio/ago. 2008.

MAIA, R. C. C.; SOARES, A. B.; VICTORA, M.S. da. Um estudo com professores da educação infantil e do ensino fundamental sobre suas habilidades sociais e inteligência geral. Estudos e pesquisas em psicologia, ano 9, n.2, p. 464-479, 2009.

MARTELETO, R. M. Redes sociais, mediação e apropriação de informações: situando campos, objetos e conceitos na pesquisa em Ciência da Informação. Pesq. bras. ci. inf., 
Brasília, v.3, n.1,p.27-46, jan./dez. 2010.

MARTINS, M. F. D; VIEIRA, J. S.; FEIJÓ, J. R.; BUGS, V. O trabalho das docentes da Educação Infantil e o mal-estar docente: o impacto dos aspectos psicossociais no adoecimento. Cadernos de Psicologia Social do Trabalho, v. 17, n. 2, p.281-289, 2014.

MOREIRA, J. C.; TOMAZZETTI, C. M. Avaliação na educação infantil e formação contínua de professores. Estud. Aval. Educ., São Paulo, v. 29, n. 71, p. 504-527, maio/ago. 2018.

PEREIRA, M. C. A formação continuada de professores da educação infantil em Sorocaba/SP. Laplage em Revista (Sorocaba), v.3, n.3, p.190-199, set.-dez.2017.

PEREIRA, H. de O. S.; MAIMONE, E. H.; OLIVEIRA, A. P. Avaliação do perfil mediacional de uma professora da educação infantil. Revista Semestral da Associação Brasileira de Psicologia Escolar e Educacional, v. 16, n. 1, jan/jun.2012.

POCINHO, M.; PERESTRELO, C. X. Um ensaio sobre burnout, engagement e estratégias de coping na profíssão docente. Educação e Pesquisa, São Paulo, v.37,n.3, p. 513 - 528, set./dez.2011.

RAMOS, M. F. H. Modelo Social Cognitivo de Satisfação no Trabalho e Eficácia Coletiva: Percepções sobre a Docência. Tese (Doutorado). Programa de Pós-Graduação em Teoria e Pesquisa do Comportamento. UFPA. Belém, 2015.

RHODEN, J. L. M.; RHODEN, V. Formação de professores: um espaço que possibilita trabalhar a educação emocional e compreender o estresse do professor. Rev. Ciênc. Ext. v.10, n.2, p. 118-135, 2014.

ROCHA, R. E. R da; FILHO, K. P.; SILVA, F. N. da; BOSCARI, M.; AMER, S. A. K,; ALMEIDA, D. C. de. Sintomas osteomusculares e estresse não alteram a qualidade de vida de professores da educação básica. Fisioter Pesqui., v. 24, n. 3, p. 259-266, 2017.

RODRIGUES; D. G.; SAHEB, D. A concepção dos professores e educadores de educação infantil sobre o saber de Morin: ensinar a condição humana. Rev. bras. Estud. pedagog. (online ), Brasília, v. 96, n. 242, p. 180-197, jan./abr. 2015.

SKAALVIK, E. M.; SKAALVIK, S. Job Satisfaction, Stress and Coping Strategies in the Teaching Profession-What Do Teachers Say? International Education Studies. v. 8, n. 3. 2015.

SILVA, F. D. A; CUNHA, A. M. de O. Representações sociais de professores da Educação Infantil sobre o desenvolvimento da prática pedagógica em meio ambiente. Ciênc. Educ., Bauru, v. 22, n. 4, p. 1013-1026, 2016.

SILVA, L. C. da; LIMA, G. E. de. Educação infantil nos desdobramentos do processo de inclusão: perspectivas de professores e equipe gestora. Regae: Rev. Gest. Aval. Educ. v. 3 n. 8 jul./dez. 2014.

SILVA, L. C. da; SALLES, T. L. de A. O estresse ocupacional e as formas alternativas de tratamento. Revista de Carreiras e Pessoas, v. 6, n. 2, Mai/Jun/Jul/Ago, 2016. 